\title{
ВЛИЯНИЕ ПОЛИМОРФИЗМА NOS3 786С/Т НА УРОВЕНЬ ОКСИДА АЗОТА У КОМОРБИДНЫХ БОЛЬНЫХ БРОНХИАЛЬНОЙ АСТМОЙ И ГИПЕРТОНИЧЕСКОЙ БОЛЕЗНЬЮ
}

\author{
А. В. Шаханов ${ }^{\square}$, О. М. Урясьев
}

Кафедра факультетской терапии с курсами эндокринологии, клинической фармакологии, профессиональных болезней,

Рязанский государственный медицинский университет имени И. П. Павлова, Рязань

\begin{abstract}
В патогенезе бронхиальной астмы и гипертонической болезни значимую роль играет оксид азота, в синтезе которого участвуют ферменты NO-синтазы. Нуклеотидный состав генов может оказывать влияние на активность фермента, поэтому представляется актуальным изучение влияния полиморфизма гена NOS3 786C/T (rs2070744) на уровни оксида азота в крови и выдыхаемом воздухе у больных, страдающих бронхиальной астмой и гипертонической болезнью. В исследовании участвовал 71 пациент. В основную группу входили 24 пациента, страдающих одновременно бронхиальной астмой и гипертонической болезнью. Еще две группы сравнения включали больных с изолированной бронхиальной астмой и больных с изолированной гипертонической болезнью. У всех пациентов определяли полиморфизм NOS3 786C/T, измеряли уровень суммарных метаболитов оксида азота в крови фоотоколориметрическим методом в реакции с реактивом Грисса и выявляли уровень выдыхаемой фракции оксида азота электрохимическим методом с помощью портативной тест-системы NObreath. Уровень метаболитов оксида азота в крови пациентов носителей генотипа CC полиморфизма NOS3 786C/T составил 69,7 (60,0; 70,4) мкмоль/л, генотипа СТ — 68,9 $(57,7 ; 77,4)$ мкмоль/л, генотипа ТТ - 67,7 $(59,7 ; 79,3)$ мкмоль/л ( $p=0,843)$. В отдельных исследуемых группах была отмечена отчетливая связь полиморфизма NOS3 786C/T и уровня оксида азота в крови. У больных бронхиальной астмой и больных гипертонической болезнью уровень метаболитов оксида азота в крови достоверно нарастает в ряду $\mathrm{CC}<\mathrm{CT}<\mathrm{T}$ ( $p=0$ 0,033 и $p=0,024$ соответственно). Таким образом, С-аллель полиморфизма NOS3 786C/T ассоциирована с более низким уровнем метаболитов оксида азота в крови больных, страдающих бронхиальной астмой и гипертонической болезнью.
\end{abstract}

Ключевые слова: астма, полиморфизм, оксид азота, гипертоническая болезнь

$\varangle$ Для корреспонденции: Антон Валерьевич Шаханов

ул. Высоковольтная, д. 9, г. Рязань, 390026; shakhanovav@gmail.com

Статья получена: 20.04.2018 Статья принята к печати: 19.06.2018

DOI: 10.24075/vrgmu.2018.029

\section{EFFECT OF THE NOS3 786C/T POLYMORPHISM ON THE LEVELS OF NITRIC OXIDE IN PATIENTS WITH ASTHMA AND COMORBID HYPERTENSION}

Shakhanov AV $\bowtie$, Uryasev OM

Department of Intermediate Therapy,

Ryazan State Medical University, Ryazan

Nitric oxide has a significant role in the pathogenesis of bronchial asthma and hypertension. Its synthesis is catalyzed by NO synthases. The nucleotide composition of genes coding for these enzymes can affect their activity; therefore, it is important to understand the effect of the NOS3 786C/T polymorphism (rs2070744) on the blood levels of nitric oxide in patients with bronchial asthma and hypertension. Our study recruited 71 individuals. The main group consisted of 24 asthmatic hypertensive patients. Two comparison groups included patients with isolated asthma and isolated hypertension. All patients were genotyped for the NOS3 786C/T polymorphism. We measured total nitric oxide metabolites in their blood using a photocolorimetric technique and the Griess reagent. The levels of nitric oxide in the exhaled air were determined electrochemically using a portable NObreath monitor. The blood levels of nitric oxide metabolites amounted to $69.7(60.0 ; 70.4) \mu \mathrm{mol} / \mathrm{l}$ in the CC genotype carriers, 68.9 $(57.7 ; 77.4) \mu \mathrm{mol} / \mathrm{l}$ in the CT genotype carriers and $67.7(59.7 ; 79.3) \mu \mathrm{mol} / \mathrm{l}$ in the patients with the TT genotype $(p=0.843)$. Individually, the groups demonstrated a clear association between the NOS3 786C/T polymorphism and the blood levels of nitric oxide metabolites. The patients with bronchial asthma and hypertension demonstrated a tendency to increasing nitric oxide levels following the pattern CC $<C T<\Pi(p=0.033$ and $p=0.024$, respectively). Thus, the C allele of the NOS3 $786 \mathrm{C} / \mathrm{T}$ polymorphism is associated with lower blood levels of nitric oxide metabolites in patients with bronchial asthma and hypertension.

Keywords: asthma, polymorphism, nitric oxide, hypertension

$\triangle$ Correspondence should be addressed: Anton V. Shakhanov

Vysokovoltnaya 9, Ryazan, 390026; shakhanovav@gmail.com

Received: 20.04.2018 Accepted: 19.06.2018

DOI: 10.24075/brsmu.2018.029 
На сегодняшний день внимание ученых все больше привлекает проблема коморбидности, изучение которой позволяет реализовать персонализированный подход к ведению пациентов. Высокую социальную значимость имеет проблема бронхиальной астмы, занимающей второе место по распространенности среди заболеваний органов дыхания. Около половины больных бронхиальной астмой страдает сердечно-сосудистыми заболеваниями, среди которых ключевое место занимает гипертоническая болезнь (13-38\%) [1]. Многие аспекты сочетанного течения бронхиальной астмы и гипертонической болезни до сих пор остаются неясными, однако не вызывает сомнения существование феномена взаимного влияния этих заболеваний [2].

Одним из возможных механизмов такого влияния является нарушение синтеза оксида азота (NO), который считается сигнальной молекулой межклеточного взаимодействия [3]. Синтез NO в эндотелии регулирует тонус сосудов, кровоток и артериальное давление, при этом нарушение его выработки способствует развитию артериальной гипертензии и формированию эндотелиальной дисфункции [4-7]. Кроме того, NO рассматривается как регулятор тонуса и просвета дыхательных путей, а в малых концентрациях препятствует бронхоспазму, что важно в предотвращении развития бронхиальной астмы [8-10].

В организме NO синтезируется из L-аргинина при участии группы цитохром P-450-подобных гемопротеинов - синтаз оксида азота (NOS), включающих три известные изоформы: нейронную (nNOS), макрофагальную (iNOS) и эндотелиальную (eNOS) [5]. Изофрормы являются продуктами экспрессии генов NOS1, NOS2 и NOS3 соответственно. Наибольшее значение в развитии атеросклероза, артериальной гипертензии и эндотелиальной дисфункции имеет эндотелиальная синтаза оксида азота, кодируемая геном NOS3. Как видно из названия, она определяется в основном в клетках эндотелия сосудов. В физиологических условиях эта изоформа конститутивна, но при различных патологических состояниях ее экспрессия индуцируется, что сопровождается повышенным образованием NO [11]. Физиологическая продукция оксида азота под действием конститутивной NO-синтазы направлена на поддержание тканевого равновесия в метаболизме NO. NO-синтазы играют важную роль в продукции NO в ранней фазе воспаления, тем самым проявляя свой провоспалительный эффект. В то же время NO-синтазы контролируют биосинтез интерлейкинов IL4, IL11, IL13, относящихся к ингибиторам воспалительной реакции. Таким образом, NO-синтазы и продуцируемый ими оксид азота оказываются «подлинными» регулятором воспаления, в том числе при бронхиальной aстме [12].

Активность экспрессии NO-синтаз напрямую зависит от нуклеотидного состава кодирующих генов. Таким образом, способность NO выступать в качестве физиологического регулятора или возможного токсического агента может быть обусловлена активностью изоформ NO-синтазы, которая изменяется при наличии мутаций генов NOS. Множество исследований посвящено изучению полиморфизма генов NOS и их роли в течение заболеваний и синтезе оксида азота, при этом роль отдельного полиморфизма в развитии многофакторных заболеваний, как правило, невелика Участие оксида азота и генов, его продуцирующих, в патогенезе бронхиальной астмы и гипертонической болезни не вызывает сомнений. Но их роль при формировании коморбидной патологии остается до конца не ясной. Среди многообразия полиморфизмов NOS3 представляется интересным изучение полиморсизма 786C/T (rs2070744) связанного с развитием ишемической болезни и инсаркта миокарда, которые также ассоциированны с нарушением эндотелиальной продукции оксида азота, как и гипертоническая болезнь [13, 14]. Целью исследования стало изучение влияния полиморфизма гена NOS3 786C/T на уровни оксида азота в крови и выдыхаемом воздухе у больных, страдающих бронхиальной астмой и гипертонической болезнью.

\section{ПАЦИЕНТЫ И МЕТОДЫ}

Работа выполнена в рамках диссертационного исследования на кафедре факультетской терапии Рязанского государственного медицинского университета имени И. П. Павлова с 2014 по 2017 годы [15]. На проведение эксперимента с участием людей получено одобрение Локального этического комитета РязГМУ (протокол № 2 от 02.10.2014г.) Этические принципы проведения исследования соответствовали требованиям Хельсинской декларации Всемирной медицинской ассоциации и правилам Надлежащей клинической практики.

В исследование включен 71 пациент, проходивший стационарное лечение в областной клинической больнице (г. Рязань) по поводу бронхиальной астмы или гипертонической болезни. Пациенты были разделены на три группы. В основную группу вошли 24 пациента, страдающих сочетанием бронхиальной астмы и гипертонической болезни. Две группы сравнения включали больных с изолированной бронхиальной астмой $(n=23)$ и больных с изолированной гипертонической болезнью $(n=24)$. Исследуемые группы были сопоставимы по полу и возрасту и включали не состоящих в родстве представителей европеоидной расы, проживающих на территории Рязанской области. Все участники подписали добровольное информированное согласие на участие в исследовании.

Критерии включения в исследование: мужчины и женщины в возрасте 45-69 лет; диагноз «бронхиальная астма, смешанная форма» и/или «Гипертоническая болезнь», установленный согласно глобальной стратегии лечения и профилактики бронхиальной астмы и рекомендаций Всероссийского научного общества кардиологов / Российского кардиологического общества соответственно. Пациентов, страдающих бронхиальной астмой, включали в исследование после купирования обострения и отмены системных ГКС или перевода на поддерживающие дозы системных ГКС, если больной получал их до поступления в стационар. Критерии исключения: беременность и период лактации; приступный период бронхиальной астмы; заболевания сердечно-сосудистой системы в стадии декомпенсации; наличие психозов и психиатрических заболеваний в анамнезе; наличие тяжелых нарушений функции печени и почек в анамнезе; наличие иных сопутствующих заболеваний и состояний, способных оказывать влияние на функцию дыхательной и сердечно-сосудистой систем и исследуемые показатели; злоупотребление и/или зависимость от психоактивных веществ Wили алкоголя. Пациенты, страдающие гипертонической болезнью в обеих исследуемых группах получали сходное лечение. Исследуемые группы не различались по количеству курящих пациентов $(p=0,441)$.

Определение суммарного уровня метаболитов оксида азота проводили в сыворотке крови фотоколориметрическим методом в реакции с использованием реактива Грисса в модификации Метельской В. А. на микропланшетном анализаторе StatFax 3200 (Awareness Technology, CША) [16]. Содержание оксида азота в выдыхаемом воздухе (FeNO) измеряли электрохимическим методом с помощью 
портативной тест-системы NObreath (Bedfont Scientific, Великобритания) согласно рекомендациям производителя. Определение генетического полиморфизма NOS3 786C/T проводили на базе Центральной научно-исследовательской лаборатории РязГМУ методом аллельспецифичной ПЦР с последующим электрофоретическим разделением продуктов амплификации с использованием реагентов компании «Литех» (Россия) на амплификаторе компании «ДНК-технология» (Россия). Материалом для молекулярно-генетического анализа служили образцы ДНК, выделенной из лейкоцитов цельной крови с помощью реагента «ДНК-экспресс-кровь» (Литех, Россия). Сопоставимость распределения аллелей изучаемых полиморфизмов в исследуемой выборке по отношению к популяции определяли путем оценки соответствия равновесию Харди-Вайнберга.

Статистический анализ проводили с помощью пакета прикладных программ StatSoft Statistica 10. Нормальность распределения признаков оценивали по критерию Шапиро-Уилка. Полученные результаты представлены в виде Ме (Q25; Q75), где Ме - медиана, а Q25 и Q75 значения нижнего и верхнего квартилей соответственно. Сравнение групп проводили с использованием критериев Краскела-Уоллиса и Манна-Уитни. Статистически значимыми считали различия при $p<0,05$.

\section{РЕЗУЛЬТАТЫ ИССЛЕДОВАНИЯ}

Результаты генетического исследования у наблюдаемых пациентов соответствовали равновесию Харди-Вайнберга $\left(\chi^{2}=0,08, p=0,77\right)$. Установлено, что в $12 \%$ случаев определялся генотип СС ( $n=9)$, в 44\% - генотип СТ $(n=31)$, в $44 \%$ - генотип ПТ $(n=31)$. Аллель С полиморфизма NOS3 786C/T выявлен в 35\% случаев ( $n=49)$, аллель Т - в 65\% случаев ( $n=93)$. Ранее нами было установлено, что у больных с сочетанием бронхиальной астмы и гипертонической болезни чаще, чем у больных с изолированной бронхиальной астмой определяется наличие Т-аллеля полиморфизма NOS3 786C/T, что указывает на участие данного полиморфизма в одновременном развитии бронхиальной астмы и гипертонической болезни [17].

При оценке влияния полиморфизма NOS3 786C/T на уровень выдыхаемой фракции оксида азота, установлено, что медиана FeNO у больных носителей CC-генотипа составляла 15 (9; 23) ppb, СТ-генотипа — 16 (13; 20) ppb,
ТТ-генотипа - 16 (9; 20) ppb. Полученные различия не были статистически значимыми $(p=0,834)$ и кроме того находились в пределах погрешности измерений тестсистемы NObreath. Аналогичные результаты получены и при оценке влияния полиморфизма NOS3 786C/T на уровень FeNO в отдельных группах (табл. 1).

Анализ взаимосвязи между генотипом NOS3 786C/T и уровнем метаболитов оксида азота в крови показал, что медиана уровня метаболитов оксида азота в крови пациентов - носителей СС-генотипа составляла 69,7 (60,0; 70,4) мкмоль/л, СТ-генотипа - 68,9 (57,7; 77,4) мкмоль/л, ТТ-генотипа - 67,7 (59,7; 79,3) мкмоль/л. Полученные различия не являются значимыми ( $p=0,843)$, что соответствует полученным нами данным о непосредственной связи полиморфизма NOS3 786C/T с развитием коморбидной патологии бронхиальной астмы и гипертонической болезни [17]. Исходя из этого, целесообразным представляется проведение оценки влияния полиморфизма NOS3 786C/T на уровень метаболитов оксида азота в каждой группе в отдельности. Так у пациентов основной группы и пациентов, страдающих гипертонической болезнью, уровень метаболитов оксида азота в крови достоверно нарастает в ряду $\mathrm{CC}<\mathrm{CT}<\mathrm{TТ}$ ( $p=0,033$ и $p=0,024$ соответственно) (табл. 2). Аналогичное нарастание отмечается и у больных, страдающих бронхиальной астмой, однако уровень статистической значимости несколько меньше ( $p=0,090)$. В целом это позволяет сделать заключение, что полиморфизм NOS3 786C/T оказывает влияние на уровень метаболитов оксида азота в крови, при этом наличие С-аллеля полиморфизма обусловливает более низкие показатели по сравнению с Т-аллелем.

\section{ОБСУЖДЕНИЕ РЕЗУЛЬТАТОВ}

Основной проблемой комплексного изучения влияния полиморфизмов на биохимические показатели у больных, страдающих бронхиальной астмой и гипертонической болезнью, является фенотипическая гетерогенность. Фенотипы заболевания ассоциированы с различными изменениями как биохимического, так и клинического статуса, что создает сложности для выявления генетических взаимосвязей с течением многофракторных заболеваний, к которым относится и бронхиальная астма, и гипертоническая болезнь. Это объясняет существование лишь небольшого количества исследований, посвященных данной проблеме.

Таблица 1. Уровень выдыхаемой фракции оксида азота в зависимости от генотипа NOS3 786C/T

\begin{tabular}{|c|c|c|c|}
\hline Генотип & БА и ГБ & БА \\
\hline СС & $22(15 ; 26)$ & $11(8 ; 13)$ & $9(9 ; 9)$ \\
\hline СТ & $16(13 ; 20)$ & $16(13 ; 20)$ & $17(13 ; 21)$ \\
\hline Т & $14(9 ; 15)$ & $20(15 ; 23)$ & $13(8 ; 20)$ \\
\hline$p$ & 0,184 & 0,062 & 0,356 \\
\hline
\end{tabular}

Примечание: БА - бронхиальная астма, ГБ — гипертоническая болезнь.

Таблица 2. Уровень метаболитов оксида азота в крови в зависимости от генотипа NOS3 786C/T

\begin{tabular}{|c|c|c|c|}
\hline Генотип & БА и ГБ & БА & ГБ \\
\hline CС & $59,5(58,9 ; 60,0)$ & $70,1(69,7 ; 73,5)$ & $43,9(43,9 ; 43,9)$ \\
\hline CТ & $68,1(60,8 ; 72,0)$ & $78,8(70,1 ; 79,7)$ & $55,6(51,6 ; 57,7)$ \\
\hline TT & $79,3(72,4 ; 84,3)$ & 0,090 & $60,4(57,0 ; 65,4)$ \\
\hline$p$ & 0,033 & 0,024 \\
\hline
\end{tabular}

Примечание: БА - бронхиальная астма, ГБ — гипертоническая болезнь. 
Так, при оценке 121 мононуклеотидного полиморфизма генов NOS1, NOS2, NOS3, показана связь уровней FeNO и полиморфизма NOS3 (NOS3 (rs743507, $p=0,004$ ) [18]. Однако в том же исследовании показана высокая гетерогенность полученных результатов. В российской популяции оценивалось влияние полиморфизма NOS3 786C/Т на уровень метаболитов оксида азота в крови здоровых юношей [19]. В этой работе, так же как и в нашем исследовании, показана связь С-аллеля полиморфизма со сниженной продукцией оксида азота и развитием эндотелиальной дисфункции. Таким образом, можно сделать заключение, что полиморфизм генов NOS1 и NOS3 способен изменять синтез оксида азота у больных, страдающих бронхиальной астмой и гипертонической болезнью, однако требуется проведение дополнительных исследований, учитывающих фенотип заболевания. В нашем исследовании не было получено статистически значимого влияния полиморфизма NOS3 786C/T на уровень метаболитов оксида азота, однако выявленная тенденция к снижению показателей у лиц, носителей
C-аллеля полиморфизма, подтверждается аналогичными литературными данными, полученными у здоровых лиц. По всей видимости высокая клиническая гетерогенность течения бронхиальной астмы требует проведения более обширных исследований для определения истинной связи полиморфизма NOS3 786C/T у больных бронхиальной астмой.

\section{ВЫВОДЫ}

С-аллель полиморфизма NOS3 786C/T ассоциирован с более низким уровнем метаболитов оксида азота в крови коморбидных больных, страдающих бронхиальной астмой и гипертонической болезнью. Уровень метаболитов оксида азота возрастает в ряду генотипов СС < СТ < ТТ полиморфизма NOS3 786C/T в крови больных, страдающих одновременно бронхиальной астмой и гипертонической болезнью, и больных с изолированной гипертонической болезнью ( $p=0,033$ и $p=0,024$ соответственно).

\section{Литература}

1. Белова И. В., Кулагин О. Л., Жестков А. В. Эпидемиология сочетания сердечно-сосудистых заболеваний и бронхиальной астмы у взрослых пациентов (на примере города Новокуйбышевска). Известия Самарского научного центра Российской академии наук. 2013; 15 (3-6): 1728-30.

2. Ходюшина И. Н., Урясьев О. М. Изменение показателей гемодинамики у больных бронхиальной астмой. Российский медико-биологический вестник им. академика И. П. Павлова. 2011; (2): 22-8.

3. Козина О. В., Огородова Л. М. Образование и биологическая роль NO при аллергическом воспалении. Бюллетень сибирской медицины. 2009; 8 (3): 95-105.

4. Лямина С. В., Ребров А. П., Лямина Н. П., Сенчихин В. Н. Диапностически значимые маркеры эндотелиальной дисфункции у больных молодого возраста с артериальной гипертонией. Регионарное кровообращение и микроциркуляция. 2007; 6 (3): 59-65.

5. Шаханов А. В., Бельских Э. С., Луняков В. А., Урясьев О. М. Клинико-патогенетическое значение определения оксида азота в крови больных бронхиальной астмой и гипертонической болезнью. Казанский медицинский журнал. 2017; 98 (4): 492-6. DOI: 10.17750/kmj2017-492.

6. Aytekin M, Aulak KS, Haserodt S, Chakravarti R, Cody J, Minai O, et al. Abnormal platelet aggregation in idiopathic pulmonary arterial hypertension: role of nitric oxide. AJP: Lung Cellular and Molecular Physiology. 2012; 302 (6): L512-L520. DOI: 10.1152/ ajplung.00289.2011

7. Kumar R, Kohli S, Mishra A, et al. Interactions between the genes of vasodilatation pathways influence blood pressure and nitric oxide level in hypertension. American journal of hypertension. 2015; 28 (2): 239-247. DOI: 10.1093/ajh/hpu130.

8. Козина О. В. Метаболизм нитрозотиолов при аллергическом воспалении. Бюллетень СО РАМН. 2010; 30 (1): 109-116.

9. Ghosh S, Erzurum SC. Modulation of asthma pathogenesis by nitric oxide pathways and therapeutic opportunities. Drug discovery today. Disease mechanisms. NIH Public Access, 2012; 9 (3-4): e89-e94. DOI: 10.1016/j.ddmec.2012.10.004.

10. Prado CM, Martins MA, Tibério IFLC. Nitric oxide in asthma physiopathology. ISRN Allergy. Hindawi Publishing Corporation, 2011; 2011: 1-13. DOI: 10.5402/2011/832560.
11. Aminuddin F, Hackett $T$, Stefanowicz D, et al. Nitric oxide synthase polymorphisms, gene expression and lung function in chronic obstructive pulmonary disease. BMC Pulmonary Medicine. BioMed Central, 2013; 13: 64. DOI: 10.1186/1471-2466-13-64.

12. Barnes PJ. NO or no NO in asthma? Thorax BMJ Group, 1996; 51 (2): 218-220.

13. Пархоменко А. Н., Кожухов С. Н., Лутай Я. М., Мойбенко А. А., Досенко В. Е. Полиморфизм Т-786С промотора гена эндотелиальной NO-синтазы: связь с эффективностью тромболитической терапии у пациентов с острым инфарктом миокарда. Украинский медицинский журнал. 2008; 4 (66): 20-23.

14. Khaki-Khatibi F, Yaghoubi A, Ghojazadeh M, et al. Association between T-786C polymorphism of endothelial nitric oxide synthase gene and level of the vessel dilation factor in patients with coronary artery disease. Molecular biology research communications. 2012; 1 (1): 1-7.

15. Шаханов А. В. Клиническое значение полиморфизма генов NOS1 и NOS3 и оксида азота у больных бронхиальной астмой и гипертонической болезнью [диссертация]. Рязань: 2017.

16. Метельская В. А., Гуманова Н. Г. Скрининг-метод определения уровня метаболитов оксида азота в сыворотке крови. Клиническая лабораторная диагностика. 2005; (6): 15.

17. Шаханов А. В., Никифоров А. А., Урясьев О. М. Полиморфизм генов синтаз оксида азота (NOS1 84G/A и NOS3 786C/T) у больных бронхиальной астмой и гипертонической болезнью. Российский медико-биологический вестник имени академика И. П. Павлова. 2017; 25 (3): 378-84. DOI: 10.23888/ pavlovj20173378-390.

18. Bouzigon E, Monier F, Boussaha M, et al. Associations between Nitric Oxide Synthase Genes and Exhaled NO-Related Phenotypes according to Asthma Status. PLoS ONE. 2012; 7 (5): e36672. DOI: 10.1371/journal.pone.0036672.

19. Хромова А. В., Феликсова О. М., Куба А. А., Бебякова Н. А. Анализ влияния структурной перестройки промотора гена NOS3 на продукцию вазоактивных эндотелиальных факторов. Журнал медико-биологических исследований. 2015; (4): 107-15. 


\section{References}

1. Belova IV, Kulagin OL, Zhestkov AV. Epidemiology of combination the cardiovascular diseases and bronchial asthma at adult patients (on example of Nokokuybyshevsk city). Izvestiya Samarskogo nauchnogo tsentra Rossiyskoy akademii nauk. 2013; 15 (3-6): 1728-30.

2. Khodyushina IN, Uryasev OM. Izmenenie pokazateley gemodinamik u bol'nykh bronkhial'noy astmoy. Rossiyskiy mediko-biologicheskiy vestnik im. akademika I.P. Pavlova. 2011; (2): 22-8.

3. Kozina OV, Ogorodova LM. Formation and biological role $\mathrm{NO}$ at an allergic inflammation. Byulleten' sibirskoy meditsiny. 2009; 8 (3): 95-105

4. Lyamina SV, Rebrov AP, Lyamina NP, Senchikhin VN. Diagnostic markers of the endothelial dysfunction in young patients with arterial hypertension. Regionarnoe krovoobrashchenie i mikrotsirkulyatsiya. 2007; 6 (3): 59-65.

5. Shakhanov AV, Belskikh ES, Lunyakov VA, Uryasev OM. Clinical and pathogenetic value of nitric oxide measurement in the blood of patients with bronchial asthma and essential hypertension. Kazanskiy meditsinskiy zhurnal. 2017; 98 (4): 492-496. DOI: 10.17750/kmi2017-492.

6. Aytekin M, Aulak KS, Haserodt S, Chakravarti R, Cody J, Minai O, et al. Abnormal platelet aggregation in idiopathic pulmonary arterial hypertension: role of nitric oxide. AJP: Lung Cellular and Molecular Physiology. 2012; 302 (6): L512-L520. DOI: 10.1152/ ajplung.00289.2011.

7. Kumar R, Kohli S, Mishra A, et al. Interactions between the genes of vasodilatation pathways influence blood pressure and nitric oxide level in hypertension. American journal of hypertension. 2015; 28 (2): 239-47. DOI: 10.1093/ajh/hpu130.

8. Kozina OV. Metabolism of nitrosothiols at an allergic inflammation Byulleten' SO RAMN. 2010; 30 (1): 109-16.

9. Ghosh S, Erzurum SC. Modulation of asthma pathogenesis by nitric oxide pathways and therapeutic opportunities. Drug discovery today. Disease mechanisms. NIH Public Access, 2012; 9 (3-4): e89-e94. DOI: 10.1016/j.ddmec.2012.10.004.

10. Prado CM, Martins MA, Tibério IFLC. Nitric oxide in asthma physiopathology. ISRN Allergy. Hindawi Publishing Corporation, 2011; 2011: 1-13. DOI: 10.5402/2011/832560
11. Aminuddin F, Hackett $T$, Stefanowicz D, et al. Nitric oxide synthase polymorphisms, gene expression and lung function in chronic obstructive pulmonary disease. BMC Pulmonary Medicine. BioMed Central, 2013; 13: 64. DOI: 10.1186/1471-2466-13-64.

12. Barnes PJ. NO or no NO in asthma? Thorax. BMJ Group, 1996; 51 (2): 218-20.

13. Parkhomenko AN, Kozhukhov SN, Lutay YaM, Moybenko AA, Dosenko VE. The T-786C polymorphism of the endothelial nitric oxide gene: connection with the efficacy of thrombolysis in patients with acute myocardial infarction. Ukrainskiy meditsinskiy zhurnal. 2008; 4 (66): 20-3.

14. Khaki-Khatibi F, Yaghoubi A, Ghojazadeh M, et al. Association between T-786C polymorphism of endothelial nitric oxide synthase gene and level of the vessel dilation factor in patients with coronary artery disease. Molecular biology research communications. 2012; 1 (1): 1-7.

15. Shakhanov AV. Klinicheskoye znacheniye polimorfizma genov NOS1 i NOS3 i oksida azota u bol'nykh bronkhial'noy astmoy i gipertonicheskoy bolezn'yu [dissertation]. Ryazan: 2017.

16. Metelskaya VA, Gumanova NG. Screening as a method for determining the serum level of nitric oxide metabolites Klinicheskaya laboratornaya diagnostika. 2005; (6): 15.

17. Shakhanov AV, Nikiforov AA, Uryasyev OM. Polymorphism of nitric oxide synthase genes (NOS1 84G/A and NOS3 786C/T) in patients with bronchial asthma and essential hypertension. Rossijskij mediko-biologicheskij vestnik imeni akademika I. P. Pavlova. 2017; 25 (3): 378-84. DOI: 10.23888/pavlovj20173378-390.

18. Bouzigon E, Monier F, Boussaha M, et al. Associations between Nitric Oxide Synthase Genes and Exhaled NO-Related Phenotypes according to Asthma Status. PLoS ONE. 2012; 7 (5): e36672. DOI: 10.1371/journal.pone.0036672.

19. Khromova AV, Feliksova OM, Kuba AA, Bebyakova NA. The effect of structural adjustment in NOS3 gene promoter on the production of endothelium-derived vasoactive factors. Zhurnal mediko-biologicheskikh issledovaniy. 2015; (4): 107-15. 